\title{
Telephone Usage and Cochlear Implant: Auditory Training Benefits
}

\author{
Aline Faria de Sousa ${ }^{1}$ Ana Claudia Martinho de Carvalho ${ }^{1}$ Maria Ines Vieira Couto ${ }^{1}$ Robinson Koji Tsuji ${ }^{2}$ \\ Maria Valéria Schmidt Goffi-Gomez ${ }^{2}$ Ricardo Ferreira Bento ${ }^{2}$ Carla Gentile Matas ${ }^{1}$ \\ Debora Maria Befi-Lopes ${ }^{1}$
}

${ }^{1}$ Department of Physiotherapy, Speech-Language Pathology \& Audiology and Occupational Therapy, Universidade de São Paulo, São Paulo, Brazil

2 Department of Otolaryngology, Universidade de São Paulo, São Paulo, Brazil

\begin{abstract}
Address for correspondence Ana Claudia Martinho de Carvalho, PhD, Department of Physiotherapy, Speech-Language Pathology \& Audiology and Occupational Therapy, University of Sao Paulo, Sao Paulo 05360-160, Brazil (e-mail: anacmartinho@usp.br).
\end{abstract}

Int Arch Otorhinolaryngol 2015;19:269-272.

\begin{abstract}
Introduction Difficulties with telephone use by adult users of cochlear implants (Cls) are reported as a limitation in daily life. Studies to improve the speech understanding of $\mathrm{Cl}$ users on the telephone are scarce in the Brazilian scientific literature.

Objective To develop and evaluate the effectiveness of a training program of auditory abilities on the telephone for an adult $\mathrm{Cl}$ user.

Resumed Report The subject was a 55-year-old woman with a degree in accounting who used a $\mathrm{Cl}$ for 24 months. The program consisted of three stages: pretraining evaluation, eight sessions of advanced auditory abilities training, and post-training evaluation. Auditory abilities with $\mathrm{Cl}$ were evaluated before and after training in three conditions: sound field, telephone with the speech processor in the microphone function, and telephone with the speech processor in the telecoil function. Speech recognition was assessed by three different lists: one with monosyllabic and dissyllabic words, another with nonsense syllables, and another one with sentences. The Client Oriented Scale of Improvement (COSI) was used to assess whether the needs estab-

\section{Keywords}

- cochlear implants

- adult

- rehabilitation

- hearing loss

- telephone lished by the $\mathrm{Cl}$ user in everyday telephone use situations improved after training. The auditory abilities training resulted in a relevant improvement in the percentage of correct answers in speech tests both in the telephone use conditions and in the sound field condition.

Conclusion The results obtained with the COSI inventory indicated a performance improvement in all situations presented at the beginning of the program.
\end{abstract}

\section{Introduction}

The demand for fast information transmission is increasingly required. Whether at work or in social interactions, the telephone is a great facilitator in everyday communication. Some individuals with severe to profound hearing loss are unable to directly use the telephone even to call for help in an emergency situation. ${ }^{1}$

received

July 3,2014

accepted after revision

August 21, 2014

published online

November 28, 2014

\section{Review of the Literature}

Adults who use hearing aids or cochlear implants encounter difficulties with telephone use due to factors such as limited acoustic gain provided by the device, limited frequency range of telephone (300 to 3,400 Hz), unfamiliar topic and speaker, previous experience on the telephone, and inability to lip-read. ${ }^{2}$ The auditory training specifically aims at improving

Copyright $\odot 2015$ by Thieme Publicações License terms Ltda, Rio de Janeiro, Brazil

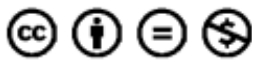

DOI http://dx.doi.org/

10.1055/s-0034-1390301. ISSN $1809-9777$. 
the speech recognition skills using only auditory cues so that the message can be understood. . $^{3,4}$

Considering the importance of telephone use in everyday life, it is of fundamental importance to develop structured programs as well as the use of appropriate instruments to assess improvement after training. ${ }^{5}$ In this scenario, the purpose of this study was to develop and evaluate an auditory skill training program directed to telephone use.

\section{Case Report}

This single case study was approved by the Ethics Committee in Research of the institution (365/2011), and the participant signed the consent form.

A 55-year-old woman with an undergraduate degree participated in the telephone auditory training program. The patient was implanted with a Nucleus 24 cochlear implant (Cochlear Corporation ${ }^{\circledR}$ ) with Freedom ${ }^{\mathrm{TM}}$ Speech Processor, 24 months prior to data collection in the right ear. She complained of progressive hearing loss of unknown etiology. She used a contralateral hearing aid without significant benefits. The average hearing threshold with cochlear implant in pretraining was of 25-dB sound pressure level.

The program consisted of three stages: pretraining assessment, eight therapeutic training sessions, and post-training assessment. The evaluation of the auditory skills with the cochlear implant before and after training was performed in three conditions: sound field, on the telephone with the speech processor in microphone function, and on the telephone with the speech processor in telecoil function (-Table 1).

The Client Oriented Scale of Improvement (COSI) was used. The COSI aims to assess the listening difficulties of individual users of hearing aids and cochlear implants and qualitatively monitor the clinical therapy evolution as perceived by the patient. ${ }^{5}$ The patient completed phase 1 of the COSI in the pretraining assessment, identifying the listening situations on the telephone that she would like to hear better and classifying the situations in order of importance. ${ }^{9}$

The therapeutic program conducted during eight 50-minute sessions was customized for the participant according to her individual characteristics and auditory skills. The difficulty level regarding the auditory skills (beginner, intermediate, or advanced) was identified and classified for the development of the training program. ${ }^{10}$ The auditory training program consisted of telephone training skills of discrimination, recognition (semiopen and open), sentence and text comprehension, and simulation of everyday situations (-Table 2). The training sessions were held with landlines located in two rooms of the laboratory (the participant and an assistant remained in one room and the speechlanguage pathologist who administered the assessment and therapeutic program remained in the other room).

The results of the procedures performed in the pre- and post-training ( - Table 3 ) indicated positive development of auditory skills. At the end of the program, the patient passed from the intermediate level to the advanced level. During pretraining assessment, the patient reported on COSI four necessities related to the use of the telephone ( - Table 4 ). After the training, the patient was instructed to rate on a scale of 0 to 5 (worse, no difference, a little better, improved, and much improved) the previously described situations. For the necessities 1,2 , and 3 , the patient scored 5 (much improved) and for necessity 4 she scored 4 (improved). The patient reported feeling more independent after training, as before she did not even try using the telephone.

\section{Discussion}

Some authors have recommended that training programs should be held in 1-hour appointments for 5 days during a period of 2 weeks, ${ }^{4}$ totaling 10 sessions. In this case study, eight treatment sessions were sufficient for the patient to report quantitative and qualitative improvement, progressing from intermediate to advanced level of auditory training. ${ }^{10}$

The program was basically prepared under three fundamental points: auditory skills, stimulus type, and condition of presentation of these stimuli (speakerphone, speech processor with microphone and with telecoil function). Results showed that there was deterioration in only one task: open set recognition of disyllabic words with the use of speech processor on the telecoil function ( $8 \%$ performance decrease in posttraining accuracy). It should be highlighted that the position of the telephone in relation to the telecoil may have contributed to the deterioration in performance of this specific task.

The patient presented the maximum score in the posttraining session in the three listening conditions when the stimuli used were lists of sentences, with an average increase of $43.3 \%$. There was an improvement in performance after training for the other stimuli (disyllables, monosyllables, and list of nonsense syllables) but with lower rates $(6.7,20$, and $13.7 \%$, respectively). The limited data evidence that the

Table 1 Evaluation of auditory skills

\begin{tabular}{|c|c|}
\hline Conditions & Tasks \\
\hline Sound field & $\begin{array}{l}\text { Threshold with modulated pulse tone at } 500,1,000,2,000,3,000,4,000 \text {, and 6,000 Hz } \\
\text { Speech recognition index with monosyllabic and disyllabic words }{ }^{6} \\
\text { List of sentences }^{7} \text { and list of nonsense syllables }\end{array}$ \\
\hline $\begin{array}{l}\text { On the telephone with the speech } \\
\text { processor in microphone function }\end{array}$ & $\begin{array}{l}\text { Speech recognition index were surveyed: monosyllabic and disyllabic words }{ }^{6} \\
\text { List of sentences }{ }^{7} \text { and list of nonsense syllables }{ }^{8}\end{array}$ \\
\hline $\begin{array}{l}\text { On the telephone with the speech } \\
\text { processor in telecoil function }\end{array}$ & $\begin{array}{l}\text { Speech recognition index were surveyed: monosyllabic and disyllabic words } \\
\text { List of sentences }^{7} \text { and list of nonsense syllables }\end{array}$ \\
\hline
\end{tabular}


Table 2 Description of training program with the eight proposed sessions

\begin{tabular}{|c|l|}
\hline Session & Planning \\
\hline 1 & $\begin{array}{l}\text { Guidance on the appropriate use of communication strategies. A flyer with recommendations and examples } \\
\text { of appropriate and maladaptive strategies was provided }\end{array}$ \\
\hline 2 & $\begin{array}{l}\text { Semiopen auditory recognition on speakerphone and simulation of the same situation on the telephone using } \\
\text { the cochlear implant microphone (proposed theme: scheduling an appointment) }\end{array}$ \\
\hline 3 & $\begin{array}{l}\text { Practice using the telephone with the cochlear implant microphone and subsequently using the telecoil. Open } \\
\text { set auditory recognition tasks with topics selected by the therapist (invitation to dinner and to watch a movie). } \\
\text { In this condition, the therapist and one assistant switched turns on the telephone so that the patient would } \\
\text { experience different voices }\end{array}$ \\
\hline 5 & $\begin{array}{l}\text { Practice using the telephone with the cochlear implant microphone and subsequently using the telecoil. Open } \\
\text { set recognition of questions on several topics (everyday life and preferences) was performed. Reading of texts } \\
\text { was initiated for further interpretation by the patient }\end{array}$ \\
\hline 6 & $\begin{array}{l}\text { Practice using the telephone with the cochlear implant microphone and subsequently using the telecoil. In this } \\
\text { session, the patient was advised to write down a recipe dictated by the speech-language pathologist via telephone. } \\
\text { Reading of texts with increased difficulty level and extent was initiated aiming subsequent interpretation }\end{array}$ \\
\hline 7 & $\begin{array}{l}\text { Practice using the telephone with the cochlear implant microphone and subsequently using the telecoil. } \\
\text { The training was performed through dictation of lists of maximum pair words and rhymes } \\
\text { noise and the task was to listen to the text and then answer specific questions related to it }\end{array}$ \\
\hline 8 & $\begin{array}{l}\text { Guidance on the use of cables available for cochlear implants and computer training of text with white } \\
\text { background noise }\end{array}$ \\
\hline
\end{tabular}

program may be effective in improving the auditory skills performance and corroborate the results of an international study. $^{11}$

Another factor that may have affected the results of the proposed training program was the presentation condition of auditory stimuli: speakerphone and telephone. In general, with different types of stimuli, the results of the current single case study indicated that performance on the telephone with speech processor in the telecoil function was equal to or better than that obtained in a soundproof booth. There is controversy in the literature regarding the effects of telephone frequency ( 300 to $3,400 \mathrm{~Hz}$ ) on the performance of auditory recognition of sentences and medial consonant when compared with natural speech, which has higherfrequency spectrum. Researchers reported that in a recognition task of phonemes with spectrum above $3,000 \mathrm{~Hz}$, the difficulty is increased on the telephone condition when compared with the open field condition speech signal bandwidth (250 to 8,000 Hz). Furthermore, researchers report an improvement in open field phoneme recognition. ${ }^{12}$ However, other authors do not agree that there is a difference between the two test settings. ${ }^{13}$

In the pre- and post-training periods, with different types of speech stimuli the auditory recognition of the patient was better with the speech processor on the telecoil function than on the microphone function (-Table 3 ).

Table 3 Results of pre- and post-training assessments

\begin{tabular}{|l|l|l|l|l|}
\hline Material & Condition & Pretraining (\%) & Post-training (\%) & Difference (\%) \\
\hline \multirow{4}{*}{ List of sentences } & Sound attenuated booth at 70 dB & 60 & 100 & 40 \\
\cline { 2 - 5 } & Telephone with telecoil & 60 & 100 & 40 \\
\cline { 2 - 5 } & Telephone with microphone & 50 & 100 & 50 \\
\hline \multirow{5}{*}{ Dissyllabic words } & Sound attenuated booth at 70 dB & 60 & 76 & 16 \\
\cline { 2 - 5 } & Telephone with telecoil & 80 & 72 & -8 \\
\cline { 2 - 5 } & Telephone with microphone & 64 & 76 & 12 \\
\hline & Sound attenuated booth at 70 dB & 52 & 80 & 28 \\
\cline { 2 - 5 } & Telephone with telecoil & 72 & 72 & 12 \\
\cline { 2 - 5 } & Telephone with microphone & 52 & 79 & 20 \\
\hline \multirow{5}{*}{ List of nonsense syllables } & Sound attenuated booth at 70 dB & 63 & 89 & 16 \\
\cline { 2 - 4 } & Telephone with telecoil & 74 & 63 & 10 \\
\cline { 2 - 4 } & Telephone with microphone & 53 & \\
\hline
\end{tabular}


272 Telephone Usage and Cochlear Implant Sousa et al.

Table 4 Necessities related to the use of the telephone (in order of importance)

\begin{tabular}{|l|l|}
\hline Necessity & \\
\hline 1 & $\begin{array}{l}\text { Talking on the phone with a particular friend } \\
\text { whose voice and speech is difficult to } \\
\text { understand even on the speaker phone }\end{array}$ \\
\hline 2 & Schedule medical appointments \\
\hline 3 & Schedule meetings with friends \\
\hline 4 & $\begin{array}{l}\text { Call customer services, such as telephone and } \\
\text { gas companies }\end{array}$ \\
\hline
\end{tabular}

Note: Results as reported by patient using the Client Oriented Scale of Improvement during the pretraining assessment.

It is noteworthy that the expectations and goals-either through COSI inventory or another self-assessment instrument-should be clear and relevant to the level at which the patient is classified. Thus, the COSI proved an important tool in the current single case study because the patient could become aware of her evolution after training when reassessing the previously set goals.

\section{Final Comments}

The proposed program proved to be viable in its application as well as fast in providing positive clinical results and improvement in quality of life of a cochlear implant user after eight sessions. Considering that the objective of this single case study was to develop a training program for telephone use, one limitation is the lack of a control case. An extended study increasing the number of patients and adding a control group would allow results compari- son and program extension to adults who use cochlear implants.

\section{References}

1 Thomas A, Lamont M, Harris M. Problems encountered at work by people with severe acquired hearing loss. Br J Audiol 1982;16(1):39-43

2 Anderson I, Baumgartner W-D, Böheim K, Nahler A, Arnoldner C, D'Haese P. Telephone use: what benefit do cochlear implant users receive? Int J Audiol 2006;45(8):446-453

3 Tye-Murray N. Foundations of Aural Rehabilitation: Children, Adults, and Their Family Members. 3rd ed. New York, NY: Delmar; 2009

4 Fu Q-J, Galvin JJ III. Maximizing cochlear implant patients' performance with advanced speech training procedures. Hear Res 2008; 242(1-2):198-208

5 Almeida K, Iório MCM. Próteses Auditivas: fundamentos teóricos e aplicações clínicas. 2nd ed. São Paulo, Brazil: Lovise; 2003

6 Momensohn- Santos TM, Russo ICP.. Prática da Audiologia Clínica. 5th ed. São Paulo, Brazil: Cortez editora; 2005

7 Costa MJ, Iorio MCM, Mangabeira-Albernaz PL. Reconhecimento de fala: desenvolvimento de uma lista de sentenças em português. Acta AWHO 1997;16(4):164-173

8 Grupo de Investigação Latino-Americano da Cochlear Corporation. Protocolo Latino Americano para Avaliação de candidatos ao Implante Coclear. Reunião do Grupo de Investigação LatinoAmericano da Cochlear Corporation. Bogotá, Colômbia; 2000

9 Stephens D. The International Outcome Inventory for Hearing Aids (IOI-HA) and its relationship to the Client-oriented Scale of Improvement (COSI). Int J Audiol 2002;41(1):42-47

10 Pedley K, Giles E, Hogan A. Adult Cochlear Implant Rehabilitation. London, UK: Whurr; 2005

11 Fu Q-J, Nogaki G, Galvin JJ III. Auditory training with spectrally shifted speech: implications for cochlear implant patient auditory rehabilitation. J Assoc Res Otolaryngol 2005;6(2):180-189

12 Fu Q-J, Galvin JJ III. Recognition of simulated telephone speech by cochlear implant users. Am J Audiol 2006;15(2):127-132

13 Hornsby BWY, Ricketts TA, Johnson EE. The effects of speech and speechlike maskers on unaided and aided speech recognition in persons with hearing loss. J Am Acad Audiol 2006;17(6):432-447 